14.11

\title{
Термоэлектрические и термоэлектрокинетические явления в коллоидных системах, модельных биологическим жидкостям живых организмов
}

\author{
(ㄱ А.В. Сидоров, ${ }^{1}$ В.М. Грабов, ${ }^{2}$ А.А. Зайцев, ${ }^{1}$ Д.В. Кузнецов ${ }^{1}$ \\ ${ }^{1}$ Елецкий государственный университет им. И.А. Бунина, \\ 399770 Елец, Липецкая обл., Россия \\ ${ }^{2}$ Российский государственный педагогический университет им. А.И. Герцена, \\ 191186 Санкт-Петербург, Россия \\ e-mail: dirnusir@mail.ru
}

Поступило в Редакцию 12 декабря 2019 г.

В окончательной редакции 17 февраля 2020 г.

Принято к публикации 17 февраля 2020 г.

\begin{abstract}
Приведены результаты экспериментальных измерений термоэлектродвижущей силы, термоэлектрокинетической ЭДС и коэффициента электропроводности в водных растворах, модельных по своим свойствам и составу человеческой крови: медицинском растворе Рингера, сывороточном альбумине, растворе Рингера, содержащем сывороточный альбумин. Проанализировано влияние органических коллоидных частиц, присутствующих в водных растворах неорганических электролитов, на величину их коэффициента термоэлектродвижущей силы. Как свидетельствуют результаты экспериментов, коэффициент термоэлектродвижущей силы исследуемых жидкостей на основе раствора Рингера имеет резкую зависимость от температуры и приобретает заметную величину в области температур, в которой функционирует живой человеческий организм. Полученный результат указывает на то, что исследуемые явления могут играть важную роль в запуске механизмов терморегуляции живых организмов.
\end{abstract}

Ключевые слова: термоэлектрический эффект, термоэлектрокинетический эффект, коллоидные растворы, кровь, альбумин.

DOI: $10.21883 /$ JTF.2020.10.49795.399-19

\section{Введение}

Для функционирования живых организмов необходимо поддержание состояния термодинамической неравновесности. Температурное поле живых организмов неравновесно и нестационарно. Известно [1], что между внутренними и приповерхностными областями живого человеческого организма разности температуры могут достигать $15 \mathrm{~K}$. Живые организмы содержат жидкие электропроводящие системы (кровь, лимфа и т.д.), непрерывно движущиеся по системам сосудов. Жидкие системы могут отличаться своим составом, цветом, величиной $\mathrm{pH}$, характером движения и выполняемыми функциями, например венозная и артериальная кровь [2]. Как было показано ранее [3], в условиях течения и перепада температуры в жидких системах живых организмов, например в крови, могут формироваться термоэлектрические и термоэлектрокинетические ЭДС.

По своему составу кровь является дисперсной системой [4]. Растворенные в ней неорганические соли, прежде всего хлориды натрия, калия и кальция, образуют ионную подсистему крови, многочисленные органические вещества обусловливают ее коллоидные свойства, присутствующие форменные элементы придают крови свойства суспензии. Как следует из состава плазмы крови, ее коллоидные свойства обусловлены, прежде всего, белками, среди которых в наибольшем количестве представлен альбумин содержанием порядка 35-45 g/L.

Термоэлектрические явления в водных растворах простых электролитов начали систематически изучаться достаточно давно [5-7], в связи с возможностью определения на их основе таких важнейших характеристик индивидуальных ионов в сильно разбавленных растворах, как их теплоты и энтропии переноса. Однако работы, посвященные изучению термоэлектрических явлений в водных растворах смесей электролитов, к каковым относится, например, ионная подсистема крови, в литературе отсутствуют, что, по-видимому, обусловлено сложностью теоретического анализа экспериментальных результатов. В коллоидных растворах эффект Зеебека изучался, прежде всего, из-за его значительного влияния на транспорт коллоидных частиц в явлении термодиффузии [8].

Цель настоящей работы - оценить величину и определить характер, формирующихся в крови в указанных выше условиях термоэлектрических и термоэлектрокинетических разностей электрических потенциалов на основе экспериментов в жидкостях, модельных по своим свойствам крови. Это позволит выяснить роль термоэлектрических и термоэлектрокинетических явлений в функционировании живых организмов. 


\section{1. Экспериментальные результаты и их обсуждение}

Для измерения термоэлектрической и термоэлектрокинетической ЭДС в жидкостях, модельных человеческой крови, использовалась экспериментальная установка на основе $U$-образной трубки, описанная в [3].

\section{1. Исследование термоэлектрических и термоэлектрокинетических свойств ионной подсистемы крови}

В качестве первой жидкости, модельной человеческой крови, для исследования был выбран медицинский раствор Рингера, который моделирует ионную составляющую крови. Раствор Рингера представляет собой смесь неорганических солей в дистиллированной воде. По своему составу он изотоничен плазме крови: $6.5 \mathrm{~g} \mathrm{NaCl}, 0.42 \mathrm{~g} \mathrm{KCl}$ и $0.25 \mathrm{~g} \mathrm{CaCl}_{2}$, растворенных в 11 дистиллированной воды [4].

В работе [3] было показано, что термоэлектрическая ЭДС раствора Рингера в области температур $20-30^{\circ} \mathrm{C}$ не превышает погрешности эксперимента, однако температурные интервалы, в которых функционирует живой человеческий организм, находятся выше $30^{\circ} \mathrm{C}$, поэтому в настоящей работе были проведены исследования термоэлектрических свойств раствора Рингера в области температур $20-42^{\circ} \mathrm{C}$. На рис. 1 представлена экспериментальная зависимость разности термоэлектрических потенциалов $\Delta \varphi$ для раствора Рингера от температуры нагреваемой области электролита. При этом температура более холодной области раствора была фиксирована и равна $22^{\circ} \mathrm{C}$.

Как видно из рис. 1, раствор Рингера имеет весьма необычную зависимость разности термоэлектрических

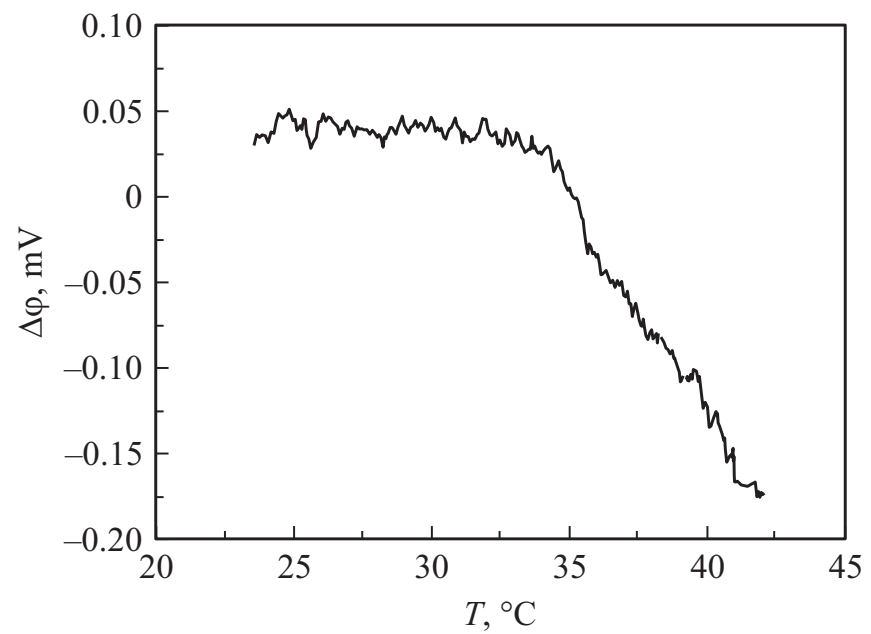

Рис. 1. Зависимость разности термоэлектрических потенциалов от температуры нагреваемой области медицинского раствора Рингера. Температура более холодной области раствора равна $22^{\circ} \mathrm{C}$.

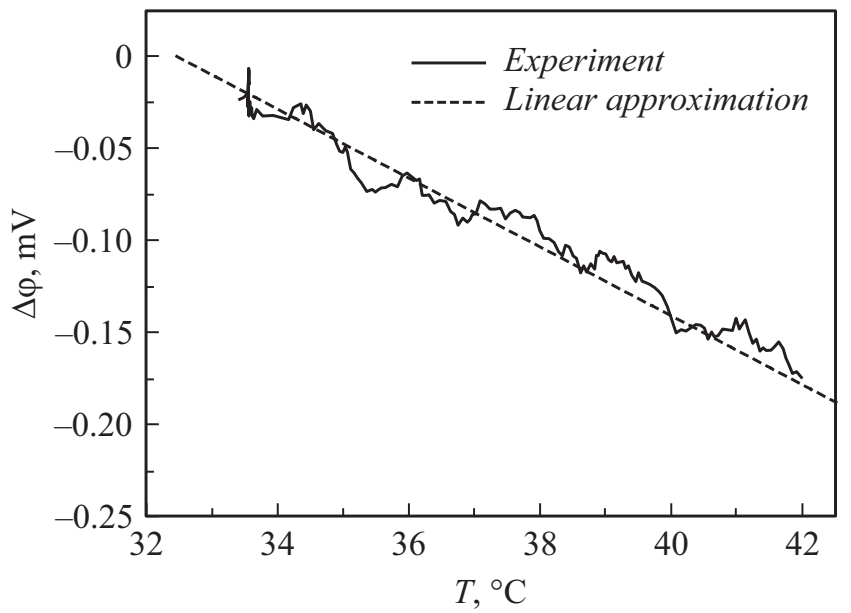

Рис. 2. Зависимость разности термоэлектрических потенциалов от температуры нагреваемой области медицинского раствора Рингера. Температура более холодной области раствора равна $33^{\circ} \mathrm{C}$.

потенциалов от температуры. При повышении температуры от 22 до $33^{\circ} \mathrm{C}$ разность потенциалов практически не меняется. Однако в области температур $33-42^{\circ} \mathrm{C}$ (т.е. в области, в которой функционирует живой человеческий организм) при создании температурного градиента в растворе Рингера генерируется термоэлектродвижущая сила. Таким образом, коэффициент термоЭДС раствора Рингера существенно нелинейно зависит от температуры. В области $22-33^{\circ} \mathrm{C}$ он близок к нулю, в области $33-42^{\circ} \mathrm{C}$ он приобретает существенную величину. В указанной области температур в растворе Рингера наблюдается линейная зависимость термоэлектрической разности потенциалов от разности температур. Величина коэффициента термоЭДС, вычисленная по результатам линейной аппроксимации экспериментальных данных, равна $\alpha=-22 \mu \mathrm{V} / \mathrm{K}$.

Так же было проведено измерение зависимости термоэлектрической разности потенциалов $\Delta \varphi$ от температуры нагреваемой области раствора для случая, когда температура более холодной области раствора поддерживалась выше комнатной и равной $33^{\circ} \mathrm{C}$ (рис. 2).

Вычисленный по результатам эксперимента коэффициент термоЭДС $\alpha=-19 \mu \mathrm{V} / \mathrm{K}$. Данное значение согласуется с измерениями, в которых температура холодной области электролита поддерживалась равной $22^{\circ} \mathrm{C}$.

Как показали эксперименты, величина термоэлектрокинетической ЭДС раствора Рингера лежит в пределах погрешности результатов эксперимента, что обусловлено достаточно низким значением его коэффициента термоЭДС. Из экспериментов в водных растворах ионных соединений следует, что наибольшими значениями величины термоэлектрокинетической ЭДС обладают водные растворы неорганических соединений, имеющих коэффициент термоЭДС порядка нескольких сотен $\mu \mathrm{V} / \mathrm{K}$ 
Результаты измерений коэффициента термоэлектродвижущей силы растворов электролитов и растворов электролитов, в которые добавлен коллоидный раствор крахмала. Доверительная вероятность для всех измерений 0.95

\begin{tabular}{|c|c|c|c|c|}
\hline № ח/п & Вещество & $\alpha, \mu \mathrm{V} / \mathrm{K}$ & $\pm \Delta \alpha, \mu \mathrm{V} / \mathrm{K}$ & Относительная погрешность, \% \\
\hline 1 & Крахмал водный коллоидный раствор & -90 & 20 & 24 \\
\hline 2 & КОН $1.5 \mathrm{~g} / \mathrm{L}$ в дистиллированной воде & -520 & 30 & 6 \\
\hline 3 & Крахмал водный коллоидный раствор в присутствии КОН $1.5 \mathrm{~g} / \mathrm{L}$ & -520 & 30 & 6 \\
\hline 4 & КОН 0.1 g/l в дистиллированной воде & -180 & 30 & 14 \\
\hline 5 & Крахмал водный коллоидный раствор в присутствии $\mathrm{KOH} 0.1$ g/L & -190 & 30 & 14 \\
\hline 6 & $\mathrm{Na}_{2} \mathrm{SO}_{4} 3.65 \mathrm{~g} / \mathrm{L}$ в дистиллированной воде & -140 & 20 & 11 \\
\hline 7 & $\begin{array}{l}\text { Крахмал водный коллоидный } \\
\text { раствор в присутствии } \mathrm{Na}_{2} \mathrm{SO}_{4} 3.65 \mathrm{~g} / \mathrm{L}\end{array}$ & -130 & 20 & 11 \\
\hline 8 & $\mathrm{KCl} 2.6 \mathrm{~g} / \mathrm{L}$ в дистиллированной воде & -23 & 7 & 30 \\
\hline 9 & Крахмал водный коллоидный раствор в присутствии $\mathrm{KCl} 2.6 \mathrm{~g} / \mathrm{L}$ & -27 & 8 & 28 \\
\hline 10 & Щавелевая кислота $1.8 \mathrm{~g} / \mathrm{L}$ в дистиллированной воде & +380 & 30 & 7.5 \\
\hline 11 & $\begin{array}{l}\text { Крахмал водный коллоидный раствор } \\
\text { в присутствии щавелевой кислоты } 1.8 \mathrm{~g} / \mathrm{L}\end{array}$ & +380 & 30 & 8 \\
\hline
\end{tabular}

(растворы щелочей $\mathrm{KOH}, \mathrm{NaOH}$, кислот $\mathrm{HCl}$, уксусная кислота и т. п.) [9].

Таким образом, величина термоЭДС раствора Рингера (раствора смеси солей в дистиллированной воде) демонстрирует необычную зависимость от температуры. Термоэлектрическая разность потенциалов возникает только в области температур выше $33^{\circ} \mathrm{C}$. В области температур $33-42^{\circ} \mathrm{C}$ величина коэффициента термоЭДС раствора Рингера по результатам серии экспериментов составляет $\alpha=-16 \pm 6 \mu \mathrm{V} / \mathrm{K}$.

\section{2. Исследование термоэлектрических свойств коллоидной подсистемы крови}

Помимо ионного компонента в состав крови входят также многочисленные органические соединения (прежде всего белки), которые образуют ее коллоидную подсистему. Поэтому следующей задачей является определение вклада данной подсистемы в величину разности термоэлектрических потенциалов крови. В связи с этим актуальным является измерение коэффициента термоэлектродвижущей силы в коллоидных растворах различной природы.

Ранее [3] было показано, что величина термоэлектрической и термоэлектрокинетической ЭДС коллоидных растворов может достигать значительных величин, например, для водного золя $\mathrm{Fe}(\mathrm{OH})_{3}$, коэффициент термоэлектрической ЭДС составляет $\alpha=+350 \mu \mathrm{V} / \mathrm{K}$, a величина термоэлектрокинетической ЭДС равна $(0.5 \pm 0.17) \mathrm{mV}$ для объемной скорости течения $8 \mathrm{~mL} / \mathrm{min}$ и перепада температур $3.5 \mathrm{~K}$.

Для оценки влияния присутствующих в крови органических коллоидных частиц на ее коэффициент термоэлектрической силы были проведены систематические эксперименты с использованием различных растворов электролитов (KOH, сернокислый натрий, хлорид калия, щавелевая кислота) при добавлении к ним коллоидного раствора крахмала. Результаты экспериментов представлены в таблице.

Основной вывод из этих экспериментов заключается в том, что термоэлектродвижущая сила смеси коллоидного раствора крахмала и раствора электролита практически всегда совпадала в пределах погрешности эксперимента с термоэлектродвижущей силой чистого раствора электролита. При этом коэффициент термоЭДС чистого коллоидного раствора крахмала довольно высок и составляет - $89 \mu \mathrm{V} / \mathrm{K}$.

Однако для других коллоидных частиц высокомолекулярных соединений вклад в термоэлектродвижущую силу смеси может превышать погрешность, как например, для коллоидного раствора куриного альбумина, для которого было зафиксировано увеличение термоЭДС смеси с электролитом КОН.

Как следует из состава плазмы крови, больше всего в ней альбумина. Поэтому на следующем этапе было проведено исследование термоэлектрических свойств раствора сывороточного альбумина. В водных растворах коллоидные частицы альбумина заряжаются отрицательно [10]. В результате коэффициент термоЭДС сывороточного альбумина отрицателен, а термоэлектрическая разность потенциалов линейно зависит от температуры (рис. 3).

Величина коэффициента термоэлектрической силы водного раствора альбумина человеческого существенно зависит от его концентрации. Зависимость носит экстремальный характер (рис. 4).

Поскольку ионный компонент крови составляют неорганические соли (в основном хлориды натрия, калия, кальция), массовый состав которых соответствует составу медицинского раствора Рингера, то необходимо 


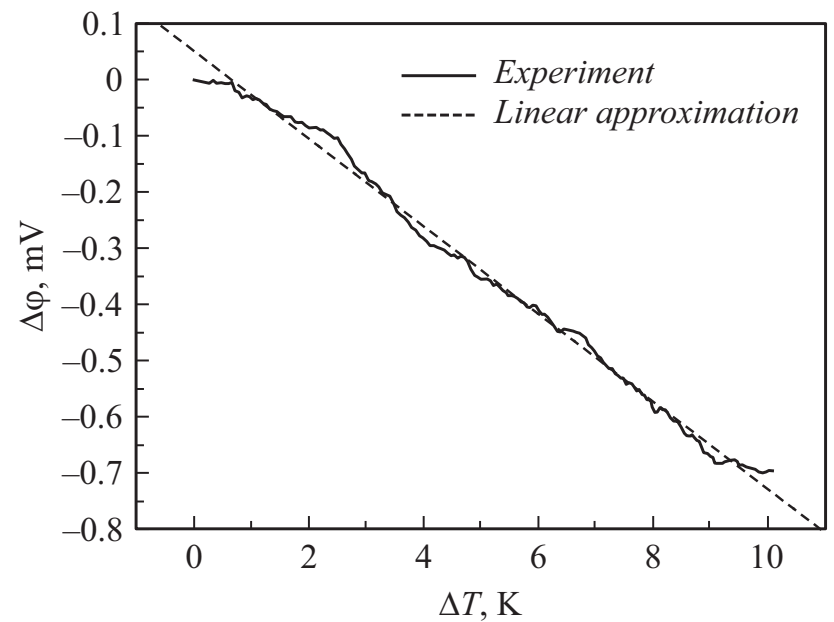

Рис. 3. Зависимость разности термоэлектрических потенциалов от разности температур для $0.5 \%$ раствора сывороточного альбумина в дистиллированной воде.

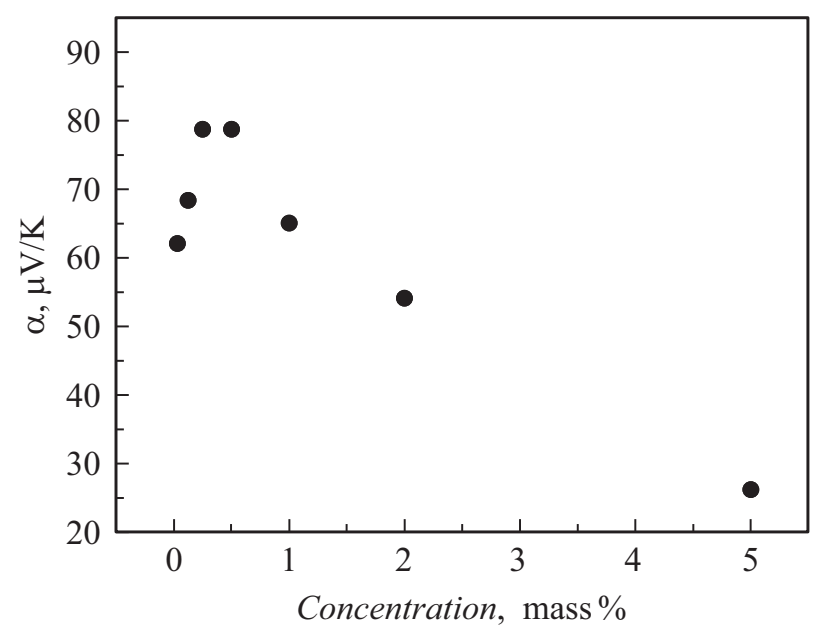

Рис. 4. Концентрационная зависимость коэффициента термоэлектродвижущей силы раствора сывороточного альбумина в дистиллированной воде от содержания альбумина.

тщательно исследовать термоЭДС раствора Рингера, содержащего коллоидные частицы белков, что является следующей задачей.

Как было показано ранее, величина коэффициента термоЭДС органических лиофобных коллоидных растворов (крахмал, куриный альбумин) с добавлением различных электролитов $\left(\mathrm{KOH}, \mathrm{Na}_{2} \mathrm{SO}_{4}, \mathrm{KCl}, \mathrm{KI}\right.$, щавелевая кислота) в основном в пределах погрешности совпадает с термоЭДС чистого электролита. Данное положение подтверждается экспериментально и для смеси альбумина в растворе Рингера при содержании альбумина не более $9.4 \mathrm{~g} / \mathrm{L}$.

Однако известно, что в нормальном состоянии в человеческой крови содержится 35-45 g/L альбумина. Как показали дальнейшие измерения, при увеличении содержания белка в смеси с раствором Рингера (рис. 5), зависимость термоэлектрической разности потенциалов от температуры претерпевает изменения в области температур выше $37^{\circ} \mathrm{C}$.

Как видно из рисунка, при увеличении массы альбумина в растворе Рингера до $22.5 \mathrm{~g} / \mathrm{L}$ термоэлектрическая ЭДС в растворе генерируется также в области температур выше $33^{\circ} \mathrm{C}$ как и для раствора Рингера, не содержащего альбумин (рис. 1). Однако в отличие от чистого раствора Рингера в растворе, содержащем альбумин, зависимость разности потенциалов от температуры носит нелинейный характер. С увеличением температуры темп роста разности потенциалов по абсолютному значению увеличивается. На зависимости можно выделить два линейных участка с разным наклоном (коэффициентом термоЭДС). В области температур $34-37.5^{\circ} \mathrm{C}$ коэффициент термоЭДС смеси равен $\alpha=-16.2 \mu \mathrm{V} / \mathrm{K}$ (совпадает с беспримесным раствором Рингера), выше этой области $\alpha=-38.3 \mu \mathrm{V} / \mathrm{K}$.

С учетом того что альбумина в человеческой крови еще больше $(35-45 \mathrm{~g} / \mathrm{L})$ можно предположить, что величина термоЭДС человеческой крови будет еще выше. Человеческий организм функционирует в непрерывно меняющихся внешних условиях, в том числе температурных. Как было показано ранее, между внутренним и приповерхностными областями организма человека температурные градиенты могут достигать $15^{\circ} \mathrm{C}$. Поэтому в кровеносной системе при таких условиях будут формироваться термоэлектрические разности потенциалов порядка десятых долей $\mathrm{mV}$.

$\mathrm{C}$ целью выяснения причины увеличения коэффициента термоэлектрической ЭДС смеси раствора Рингера, содержащего коллоидные частицы альбумина, также были проведены измерения зависимости коэффициента электропроводности раствора Рингера от содержания альбумина в нем. Измерения проводились с помощью лабораторного кондуктометра Mettler

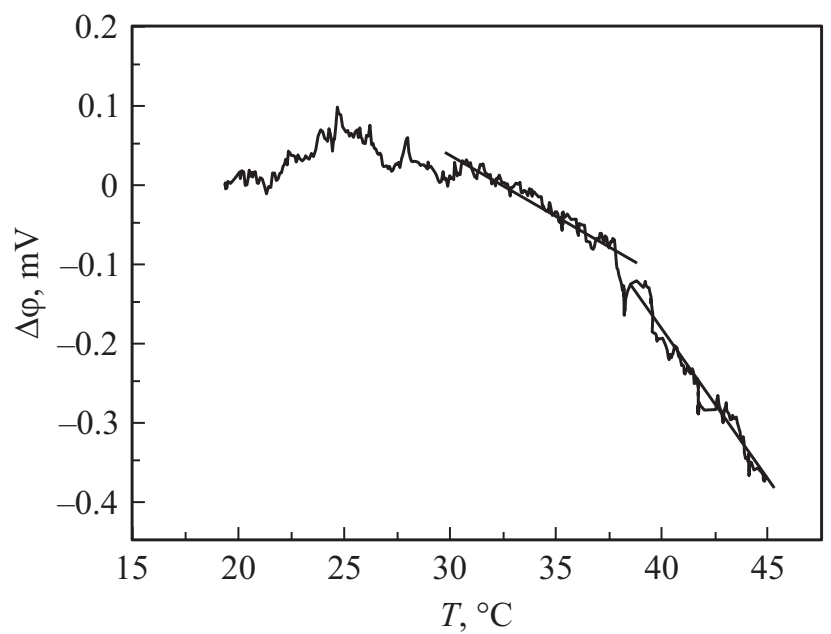

Рис. 5. Зависимость термоэлектрической разности потенциалов от температуры нагреваемой области для смеси $22.5 \mathrm{~g}$ альбумина на $1 \mathrm{~L}$ раствора Рингера. Температура более холодной области раствора равна $20^{\circ} \mathrm{C}$. 
Toledo S30. Как показали измерения, коэффициент электропроводности раствора слабо уменьшается с увеличением содержания в нем альбумина от значения $\sigma=56.5 \pm 0.5 \mu \mathrm{S} / \mathrm{cm}$ для беспримесного раствора Рингера до значения $\sigma=54.0 \pm 0.5 \mu \mathrm{S} / \mathrm{cm}$ для раствора, содержащего $22.5 \mathrm{~g} / \mathrm{L}$ альбумина. При этом величина коэффициента термоэлектрической ЭДС в области температуры выше $37.5^{\circ} \mathrm{C}$ увеличивается почти в два раза.

Как известно коэффициент электропроводности среды $\sigma$ можно выразить через величины подвижности заряженных частиц $u_{i}$, например ионов электролита, с помощью соотношения [11]

$$
\sigma=F \sum_{i}\left|z_{i}\right| c_{i} u_{i}
$$

где $F$ - постоянная Фарадея, $z_{i}$ - электрический заряд частицы в единицах заряда электрона, $c_{i}$ - объемная концентрация частиц вида $i$. Сумма в соотношении (1) распространяется на все виды заряженных частиц в растворе, т.е. ионы электролита и коллоидные частицы альбумина. Известно, что электропроводность коллоидных растворов определяется главным образом ионами электролита, вклад заряженных коллоидных частиц мал [12]. Поэтому факт уменьшения коэффициента электропроводности ионного раствора Рингера, содержащего альбумин, может быть объяснен либо уменьшением значений подвижностей ионов $u_{i}$, либо уменьшением их концентрации $c_{i}$, например, за счет процессов присоединения анионов частицами альбумина.

С другой стороны, коэффициент термоэлектродвижущей силы раствора $\alpha=\Delta \varphi / \Delta T$ в начальные моменты времени, когда в растворе еще не сформировались высокие градиенты концентрации, определяется суммой произведений подвижностей заряженных частиц $u_{i}$ на их теплоту переноса $Q_{i}[11]$

$$
\alpha \propto-\sum_{i} \frac{u_{i} Q_{i}}{T z_{i}} .
$$

Известно, что коллоидные растворы обладают рекордными значения коэффициента Соре по сравнению с растворами истинных электролитов [13-15] благодаря высоким значениям теплоты переноса $Q_{i}$ коллоидных частиц, которые могут превышать значения $Q_{i}$ для ионов на три порядка. Поэтому естественно связать увеличение коэффициента термоэлектрической силы раствора Рингера, содержащего сывороточный альбумин, с коллоидными частицами альбумина, имеющими высокие значения теплоты переноса. Однако существенный вклад в коэффициент термоЭДС они начинают вносить только при их высокой концентрации и, начиная с температуры $37.5^{\circ} \mathrm{C}$.

\section{Заключение}

Таким образом, проведенные экспериментальные измерения в различных жидкостях, модельных человеческой крови, позволяют сделать следующие выводы.
1. Характер зависимости термоэлектрических разностей потенциалов от температуры определяет, главным образом, ионная составляющая плазмы крови, моделью которой является раствор Рингера. Причем коэффициент термоЭДС раствора Рингера приобретает заметную величину только в ограниченной области температур более $33^{\circ} \mathrm{C}$, т.е. в той области, в которой функционирует живой человеческий организм. В этой области температур коэффициент термоЭДС раствора Рингера по результатам серии экспериментов составляет $\alpha=-16 \pm 6 \mu \mathrm{V} / \mathrm{K}$.

2. Присутствующие в человеческой крови белки (прежде всего альбумин) не изменяют существенно характер зависимости разности термоэлектрических потенциалов раствора Рингера от температуры, оставляя неизменным его главную особенность: резкую зависимость коэффициента термоЭДС от температуры.

3. В то же время с увеличением концентрации коллоидных частиц белка происходит существенное изменение величины коэффициента термоЭДС раствора Рингера в чувствительной области температур $33-42^{\circ} \mathrm{C}$. В этой области коэффициент термоЭДС раствора Рингера при содержании альбумина $22.5 \mathrm{~g} / \mathrm{L}$ увеличивается почти в два раза.

4. Совместный анализ экспериментальных результатов по измерению электропроводности и коэффициента термоЭДС раствора Рингера, содержащего сывороточный альбумин, свидетельствует о том, что данный факт обусловлен, по-видимому, большими значениями теплоты переноса коллоидных частиц $Q_{i}$ по сравнению с ионами.

Все это позволяет сделать следующее предположение о роли термоэлектрических и термоэлектрокинетических явлений в функционировании живых организмов.

Если учесть, что для поддержания нормального функционирования человеческого организма необходимо поддерживать строго определенные температурные интервалы в крови, причем принципиально важен верхний температурный предел, за что отвечают механизмы терморегуляции, то с учетом полученных результатов можно предположить, что термоэлектрические и термоэлектрокинетические разности потенциалов, формирующиеся при температурах выше примерно $35^{\circ} \mathrm{C}$, могут играть важную роль в запуске механизмов терморегуляции живых организмов.

\section{Финансирование работы}

Исследование выполнено при финансовой поддержке РФФИ и администрации Липецкой области в рамках научного проекта 19-42-480001.

\section{Конфликт интересов}

Авторы заявляют, что у них нет конфликта интересов. 


\section{Список литературы}

[1] Гуляев Ю.В., Годик Э.Э., Дементиенко В.В. // Достиж. AH CCCP. 1988. T. 229. № 5. C. 1259-1262.

[2] Фундаментальная и клиническая физиология. / Под ред. А.Г. Камкина, А.А. Каменского. М.: Академия, 2004. $1073 \mathrm{c}$.

[3] Грабов В.М., Зайщев А.А., Кузнещов Д.В., Сидоров А.В. // ЖТФ. 2018. Т. 88. Вып. 10. С. 1462 1466. DOI: $10.21883 / \mathrm{JTF} .2018 .10 .46486 .8-1$ [Grabov V.M., Zaitsev A.A., Kuznetsov D.V., Sidorov A.V. // Tech. Phys. 2018. Vol. 63. N 10. P. 1415-1419.]

[4] Гистология, цитология и эмбриология / Под ред. Ю.А. Афанасьева, С.Л. Кузнецова, Н.А. Юриной. М.: Медицина, 2006. $768 \mathrm{c}$.

[5] Agar J.N. // Revs. Pure Appl. Chem. 1958. Vol. 8. N 1. P. 32 41.

[6] Breck W., Cadenhead G., Hammerl M. // Trans. Faraday Soc. 1965. Vol. 61. P. 37-49.

[7] Payton A.D., Boyd B.H., Houck C.M., Temple E.H., Zimmerman A.H. // J. Electrochem. Society. 1973. Vol. 120. N 3. P. 373-378.

[8] Kyriakos A.E., Majee A., Maskos M., Würger A. // Soft Matter. 2014. Vol. 10. N 12. P. 1931-1936.

DOI: $10.1039 / \mathrm{c} 3 \mathrm{sm} 52779 \mathrm{~d}$

[9] Грабов В.М., Зайщев А.А., Кузнецов Д.В., Сидоров А.В., Новиков В.И. // Вестник МГТУ им. Н.Э. Баумана. Сер. „Естественные науки“. 2008. № 3. С. 112-122.

[10] Гауровити Ф. Химия и биология белков. М.: ИИЛ, 1953. $435 \mathrm{c}$.

[11] Хаазе P. Термодинамика необратимых процессов. М.: Мир, 1967. 545 с.

[12] Духин С.С. Электропроводность и электрокинетические свойства коллоидных систем. Киев: Наукова думка, 1975. $126 \mathrm{c}$.

[13] Морозов К.И. // ЖЭТФ. 1999. Т. 115. Вып. 5. С. 1721-1726.

[14] Piazza R., Guarino A. // Phys. Rev. Lett. 2002. Vol. 88. N 20. P. 208302. DOI: 10.1103/PhysRevLett.88.208302

[15] Braibanti M., Vigolo D., Piazza R. // Phys. Rev. Lett. 2008. Vol. 100. N 10. P. 108303.

DOI:https://doi.org/10.1103/PhysRevLett.100.108303 